\title{
IN-SITU MEASURING INDOOR ENVIRONMENTAL QUALITY IN PUBLIC KINDERGARTEN IN SLOVENIA. A CASE STUDY
}

\author{
DOI: 10.18485/arh_pt.2020.7.ch27
}

\begin{abstract}
- Vesna Lovec
University of Maribor, Faculty of Civil Engineering, Transportation Engineering and Architecture, Slovenia, Smetanova ulica 17, Maribor 2000, vesna.lovec@um.si

\section{_ Miroslav Premrov}

University of Maribor, Faculty of Civil Engineering, Transportation Engineering and Architecture, Slovenia, Smetanova ulica 17, Maribor 2000,miroslav.premrov@um.si
\end{abstract}

\section{- Vesna Žegarac Leskovar \\ University of Maribor, Faculty of Civil Engineering, Transportation Engineering and Architecture, Smetanova ulica 17, Maribor 2000, vesna.zegarac@um.si}

\begin{abstract}
The number of children in Slovenia, who are enrolled in kindergartens, is increasing, however, the indoor environmental quality (IEQ) in kindergartens remains poorly investigated. Younger children are a vulnerable population, so the IEQ is extremely important for their well-being and growth. Therefore, it is essential to investigate and evaluate indoor conditions of kindergartens.

This study presents the results of the IEQ assessment based on objective evaluation by monitoring crucial indoor conditions in the public kindergarten located within a residential area in the city of Maribor, Slovenia. The research includes in-situ measurements in the kindergarten classroom during the heating season. Selected comfort parameters were simultaneously measured and investigated: the concentrations of carbon dioxide $\left(\mathrm{CO}_{2}\right)$, air temperature and air humidity. Measurements were taken continuously during a period of twelve days. Besides monitoring, other analyses were conducted: the building thermal envelope, building construction, building site and environment, heating, occupant's behaviour, etc.
\end{abstract}

The purpose of this study is to investigate and analyse elements of IEQ in the chosen kindergarten. Moreover, the aim is to investigate whether selected comfort parameters fulfil the requirements of regulations and standards for the kindergartens. The goal is also to analyse the occupant's behaviour and to study its relation to the IEQ pattern during the day and among working and non-working days. The results clearly indicate periods of high air temperature, dry air and high level of $\mathrm{CO}_{2^{\prime}}$ therefore measures for improvement of IEQ elements are discussed.

KEYWORDS _ Indoor Environmental Quality (IEQ), kindergarten, in-situ measurements

\section{INTRODUCTION}

The environment, where children live, grow and learn, plays an important role in their growth and development. Most of the children in Slovenia spend their early childhood in kindergartens; statistical data of the Republic of Slovenia show that $81.7 \%$ of all children aged between 1 and 5 are enrolled in kindergartens [14]. 
A kindergarten presents the child's physical, biological and social environment. Children daily spend approximately 9 hours in an educational institution, therefore it is important that this does not present the health hazard for them. Poor quality of the indoor environment in the kindergartens can negatively affect the comfort and health of the users - children as well as employees [6]. Numerous studies of educational institutions in Slovenia and worldwide have exposed the problem of thermal discomfort [3], light discomfort [5], poor quality of the indoor air [16], and acoustic discomfort [8]. However, the topic of pre-school buildings in Slovenia is poorly researched, there is a lack of studies with continuous in situ measurements of the parameters of the indoor comfort in the rooms, where children spend lots of their time.

This research aims to evaluate parameters of the Indoor Environment Quality (IEQ) in the playroom of the chosen kindergarten in Maribor, Slovenia. The estimation includes the analysis of the single parameters of the thermal comfort and the quality of the indoor air based on the results of the in situ measurements in the kindergarten playroom. The goal is to determine each parameter of thermal comfort and the quality of the indoor air in the playroom and to compare the results with applicable legislation and standards. Potential deficiencies in the quality of the indoor living environment will result in the definition of the problems and the suggestion for possible improvements.

\section{IEQ PARAMETERS - APPLICABLE LEGISLATION AND RECOMMENDATIONS}

The appropriate Indoor Environment Quality (IEQ) is guaranteed by suitable thermal comfort, proper air quality (IAQ), light and acoustic comfort. Thus, IEQ is very complex and depends on numerous interdependent parameters and tremendously affects health and well-being of people, especially children. Namely, children's respiratory and immune system is much more sensitive than the adult system, so children are very sensible to the environmental influences. Therefore, the IEQ is even more important in pre-school buildings. This research includes determination of the optimal value of each parameter of thermal comfort and air quality according to critical assessment of applicable legislation, recommendations and previous studies considering the pre-school buildings. Comparison with the measured values would be also conducted.

\section{Thermal comfort}

The assessment of the thermal comfort includes continuous measurements of the indoor air temperature Tai $\left[{ }^{\circ} \mathrm{C}\right]$ and relative air humidity $\mathrm{RHai}[\%]$ in the playroom of the kindergarten. Previous studies show that poor thermal conditions in the room negatively affect children's health, well-being and ability to learn [2]. In addition, children are more sensitive to high air temperatures than adults and also to changes in thermal comfort which impact their metabolism [16].

Indoor air temperature Tai $\left[{ }^{\circ} \mathrm{C}\right]$ in the kindergartens is determined in Slovenia by Rules of standards and minimal technical conditions for kindergarten premises and equipment which prescribe minimum air temperature $20^{\circ} \mathrm{C}$, but do not limit maximal air temperature [11]. Regulations about air conditioning in building determine the parameter for the thermal comfort of the sitting person in the living area which includes the air temperature in heating season between $19{ }^{\circ} \mathrm{C}$ and $24{ }^{\circ} \mathrm{C}$, although recommended temperature is $20^{\circ} \mathrm{C}$ to $22^{\circ} \mathrm{C}$ [12]. In addition, regulations define the surface temperature of the floor between $17^{\circ} \mathrm{C}$ and $26^{\circ} \mathrm{C}$. However, numerous studies recommend the air temperature in kindergartens $21{ }^{\circ} \mathrm{C}$ and point out that children feel more comfortable at lower temperatures.

Relative air humidity RHai [\%] in pre-school buildings is also determined by Regulation of standards and minimal technical conditions for kindergarten premises and equipment [11], which declares that the area of ventilation and its parameters is determined by applicable technical standards, i.e. with Rules on ventilation and air conditioning of buildings, which define that the air temperature between $20{ }^{\circ} \mathrm{C}$ and $26{ }^{\circ} \mathrm{C}$ requires relative humidity between $30 \%$ in $70 \%$ [12]. Moreover, the Rules define the necessary additional mechanical ventilation in the changing rooms and toilets for kids. The ideal air humidity in the rooms, where children stay during the day, is between 45 and $55 \%$ at a suitable air 
temperature between 20 in $22{ }^{\circ} \mathrm{C}[10]$.

\section{Air quality}

One of the basic parameters which indicates the poor air quality is carbon dioxide concentration (CO2) in the air. The most $\mathrm{CO} 2$ in the room is produced by the human breathing, therefore is the number of occupants and their activities a key factor for $\mathrm{CO} 2$ concentration. In proportion to their weight, children breath larger air volume than adults; besides a playroom is occupied by higher concentration of occupants comparing to office for example, so the indoor air pollutants accumulate much faster [9]. In addition to human factor (breathing), the factors which also impact the concentration of $\mathrm{CO} 2$ in the scientific literature are: ventilation equipment, furniture and activities in a room (the number of occupants and activities).

The Rules on ventilation and air conditioning of buildings of the Republic of Slovenia determines value $1660 \mathrm{ppm}$ as the maximal allowed $\mathrm{CO} 2$ indoor concentration [2]. According to the recommendations of the American Society of Heating, Refrigerating and Air Conditioning Engineers (ASHRAE), the acceptable $\mathrm{CO} 2$ concentration level depend on outdoor $\mathrm{CO} 2$ concentration [1]. The difference between indoor and outdoor $\mathrm{CO} 2$ concentration should not exceed $700 \mathrm{ppm}$. Assuming that the average $\mathrm{CO} 2$ concentration values in the outdoor air are $400 \mathrm{ppm}$, the indoor $\mathrm{CO} 2$ concentration values should be under $1100 \mathrm{ppm}$. In this respect, the ASHRAE recommendations are much stricter than Slovene Rules.

\section{IEQ parameters - impact on human health and well-being}

The inappropriate indoor air temperature and humidity is especially dangerous for the vulnerable group such as small children. The indoor air temperature is analysed in the heating season and depends on the heating regime, while the indoor air humidity is influenced by user activity, their living habits and the frequency of room ventilation. The consequences of insufficient air humidity control and high air humidity are good conditions for mould growth and development which negative health influence is proved [17]. On the other hand, the consequences of the dry air can be dried mucous membranes, lips, skin and scalp, increasing infections and respiratory illness, tension, tiredness and lack of concentration.

The impact of $\mathrm{CO} 2$ on health and well-being of occupants is the subject of many international studies. The exposure to higher concentrations of carbon dioxide could results in many different symptoms such as cold, eye irritation, dry mucous membrane, headache, dry skin and lethargy (a pathological state of sleepiness). The normal outdoor CO2 concentration is between 250-350 ppm, whereas the indoor $\mathrm{CO} 2$ concentration with effective ventilation should be between $350-1000 \mathrm{ppm}$. The indoor air $\mathrm{CO} 2$ concentration higher than $1000 \mathrm{ppm}$ can result in potential complaints of sleepiness and poor air quality, while the indoor CO2 concentration above $2000 \mathrm{ppm}$ indicates the used, stuffy air. This can cause headaches, sleepiness, insufficient concentration, lack of focus, accelerated heart rate and slight nausea [18]. In addition to acute health problems, the increased $\mathrm{CO} 2$ concentration can mean higher risk for different respiratory diseases. The studies show that children in kindergartens are subjected to higher risk for asthma and allergy problems in comparison with children who do not attend kindergartens [14].

In addition, high $\mathrm{CO} 2$ concentration can be an indicator of the presence of other pollutants in the air such as carbon monoxide and formaldehyde which can negatively impact respiratory organs [1]. Occurrence of the most chemical and biological pollutants can hurt respiratory organs, especially children's, who are more sensitive due to undeveloped immune system [13]. The other air pollutants are not the subject of this research; however, their presence is indicated if there is highly increased measured $\mathrm{CO} 2$ concentration in the playroom of the kindergartens. 


\section{A CASE STUDY}

The building of the chosen kindergarten was constructed in 1981. It is located in a peaceful residential neighbourhood. In terms of design, architecture and structure, it composes a whole with a block of flats, which was built at the same time. The kindergarten is built in a massive structural system; the area of the kindergarten is $3217 \mathrm{~m}^{2}$, it includes basement, ground floor and two floors. The kindergarten homes 17 groups (playrooms). The service facilities (kitchen, storage, etc.) are in the basement. The building has a remote heating, regulated according to the outdoor air temperature. Two radiators are placed directly under the window in the playroom. During the heating season, the heating is not turning off, the temperature in the system gets lower.

The measurements in this research were performed in the south oriented playroom on the ground floor of the building. During the measuring period, a mixed group of children, aged 1 to 3 , occupied the playroom. The number of children enrolled in group is 14 and two educators (during the working days among the holidays, the maximal number of children were exceeded due to a technical reason; playroom was occupied by 15 children). The playroom is mostly in its original state from 1981, the majority of the built-in furniture is also from 1981, with an exception of some pieces of movable furniture. The original windows are replaced by the double-glazed PVC windows. The hard wood floor is original. The playroom area is $47.3 \mathrm{~m}^{2}$ without associated sanitary facilities, the playroom volume is $104.06 \mathrm{~m}^{3}$, its orientation is south. The windows are shaded by exterior blinds and decorative curtains inside. The playroom does not have air conditioners. The ventilation is only natural by opening windows, without ventilations system (Figure 1).
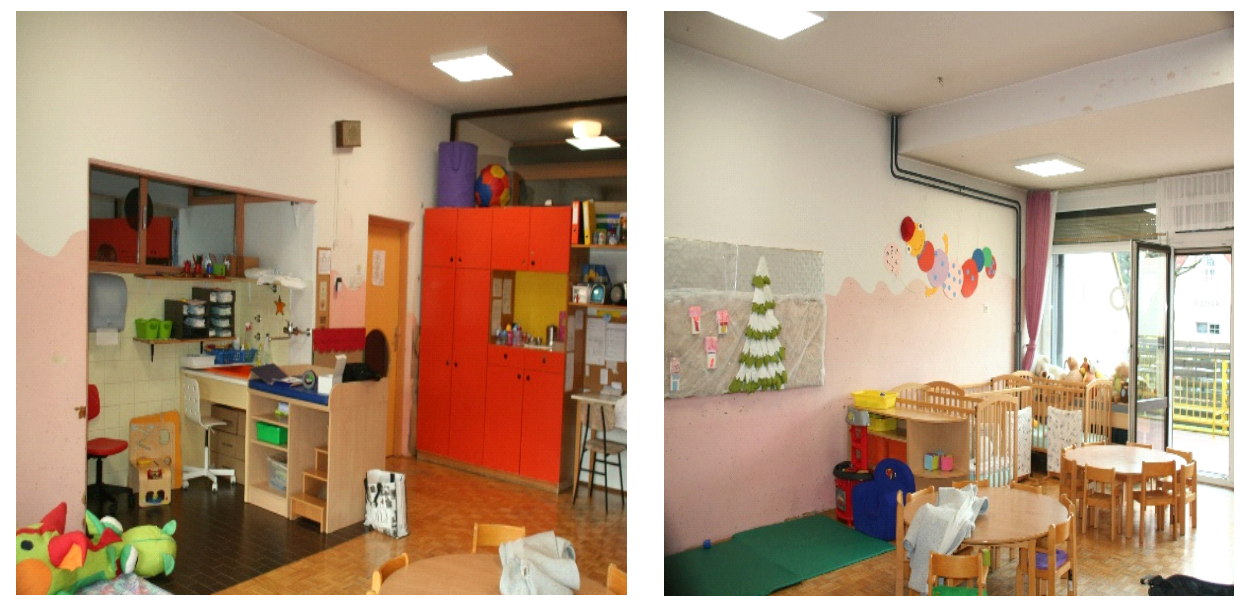

_. Figure 1: The playroom

The chosen playroom presents a typical playroom in a Slovene kindergarten, built in the decade between 1970 and 1980, when the majority of the pre-school buildings was erected. In terms of energy renovation, the only intervention was the windows replacement, which is the most common intervention on the most of the buildings from this period. Therefore, the case study can indicate the current thermal comfort and indoor air quality state of the Slovene pre-school buildings in general.

\section{MEASUREMENTS IN SITU}

The experimental analysis of the IEQ included continuous in situ measurements of the chosen parameters of thermal comfort and indoor air quality. In terms of thermal comfort, the measurements of the indoor air temperature Tai $\left[{ }^{\circ} \mathrm{C}\right]$, relative indoor air humidity $\mathrm{RHai}[\%]$ and surface temperature 
of the floor Tsurf $\left[\mathrm{C}^{\circ}\right]$ were carried out. The measured parameter of the indoor air quality was the carbon dioxide concentration $\mathrm{CO} 2$ [ppm]. The light and acoustic comfort in the playroom are not the subject of this research.

The measurements in situ were performed continuously for 15 days. The chosen period included working days, weekends and holidays during the heating season. The winter was chosen for the measurements because of the increased indoor air pollution and high concentration of the harmful substances in the air, due to the structure seal and low level of ventilation [7]. The number of present children and their activities in the playroom were daily recorded as well as the ventilation intervals. The playroom was occupied each working day from 5:00 am to 3:30 pm. During the day the average ventilation lasted from 10 to 20 minutes three times a day, the dynamics and intensity of ventilation was chosen by the educators. Namely, they noticed that the room was too warm. During the measurements the daily range of outside air temperatures was from $-8^{\circ} \mathrm{C}$ up to $15^{\circ} \mathrm{C}$.

The location and height of the measurement devices were tailored according to the activities of the playroom occupants. The obstacle in the measurement process was the fact that the playroom was used by toddlers, so the devices should not present the potential dangerous and at the same time the devices should be secured or hidden so that children could not jeopardize the measurement procedures. The main device was situated on the shelf above the educator's desk at the height of $1.5 \mathrm{~m}$. The devices recorded the data every fifteen minutes. The following measurement devices were used: the data logger rotatronic CL 11 was used for Tai, RHai and CO2 measurements, the additional devices volcraft were installed for Tai, RHai measurements and the belmet flir $\mathrm{mr} 77$ was used for Tsurf measurements. The aim of multi measurement devices was the comparison of result deviations and monitoring of parameters of indoor comfort in different specific points in the playroom: room for nursing, sleeping, staying, etc. The measurements were carried out in the frame of the research project VRTEC+, which included measurements in pre-school buildings throughout Slovenia.

\section{RESULS}

Measurement results of the Tai, RHai and $\mathrm{CO} 2$ are shown in Table 1. Minimal, maximal and average values of all measurement points are displayed for the period when occupants were in the playroom, daily from $5.00 \mathrm{am}$ to $3.30 \mathrm{pm}$. The recorded measurement points during the time when the playroom was closed, was not considered (Day 3,4,6,7,10,11,13,14 in table). The register of the number of present children and also two educators, who were present every day, was kept on a daily basis.

- Table 1: Measured data

\begin{tabular}{|l|c|c|c|c|c|c|c|c|c|c|}
\hline & \multirow{2}{*}{$\begin{array}{c}\text { No. of } \\
\text { occupa } \\
\text { nts }\end{array}$} & \multicolumn{3}{|c|}{$\mathbf{R H}_{\text {ai }}$ [\%] } & \multicolumn{3}{c|}{$\mathbf{T}_{\text {ai }}{ }^{\circ} \mathbf{C}$ ] } & \multicolumn{3}{c|}{$\mathbf{C O}_{\mathbf{2}}$ [ppm] } \\
\cline { 3 - 11 } & & $\max$ & avg & $\min$ & $\max$ & avg & $\min$ & $\max$ & avg \\
\hline \hline Day 1 & 7 & 31.2 & 39.3 & 35.1 & 21.7 & 23.2 & 22.7 & 499 & 1524 & 1027.7 \\
\hline Day 2 & 10 & 25.7 & 36.4 & 30.9 & 20.3 & 23.6 & 22.9 & 469 & 1807 & 1029.0 \\
\hline Day 3 & $/$ & & & & & & & & & \\
\hline Day 4 & $/$ & & & & & & & & & \\
\hline Day 5 & 10 & 25.6 & 37.3 & 30.3 & 20.7 & 24.6 & 23.9 & 472 & 1687 & 1087.2 \\
\hline Day 6 & $/$ & & & & & & & & & \\
\hline Day 7 & $/$ & & & & & & & & & \\
\hline Day 8 & 15 & 21.8 & 37.2 & 26.8 & 20.9 & 23.6 & 22.9 & 461 & 2452 & 1112.3 \\
\hline Day 9 & 15 & 23.8 & 34.6 & 28.1 & 21.3 & 24.4 & 23.7 & 496 & 2035 & 1095.3 \\
\hline Day 10 & $/$ & & & & & & & & & \\
\hline Day 11 & $/$ & & & & & & & & & \\
\hline Day 12 & 14 & 20.2 & 27.4 & 25.9 & 20.5 & 24.83 & 24.2 & 457 & 2009 & 1112.0 \\
\hline Day 13 & $/$ & & & & & & & & & \\
\hline Day 14 & $/$ & & & & & & & & & 1008.0 \\
\hline Day 15 & 15 & 16.9 & 27.4 & 23.6 & 18.2 & 24.2 & 22.7 & 410 & 1536 & 10 \\
\hline
\end{tabular}


The measured results of the air humidity RHai [\%] show rather dry air with the average values between 25.9 to $35.1 \%$, although within the range of applicable legislation demands. Not even one measurement point reached recommended values from 45 to $55 \%$. Therefore, the children stayed in considerably dry rooms (Figure 1).

The average measured air temperature Tai $\left[{ }^{\circ} \mathrm{C}\right]$ is between 22.7 to $23.9^{\circ} \mathrm{C}$, which meets the recommended values. Also all single measurement points are between $19^{\circ} \mathrm{C}$ and $24^{\circ} \mathrm{C}$. Therefore, the indoor air temperature also meets the applicable legislation demands. Overall indoor air temperature in playroom is a bit higher compared to international standards, health recommendations and recommendations of the previous studies which consider the optimal air temperature $22^{\circ} \mathrm{C}$ (Figure 3 ).

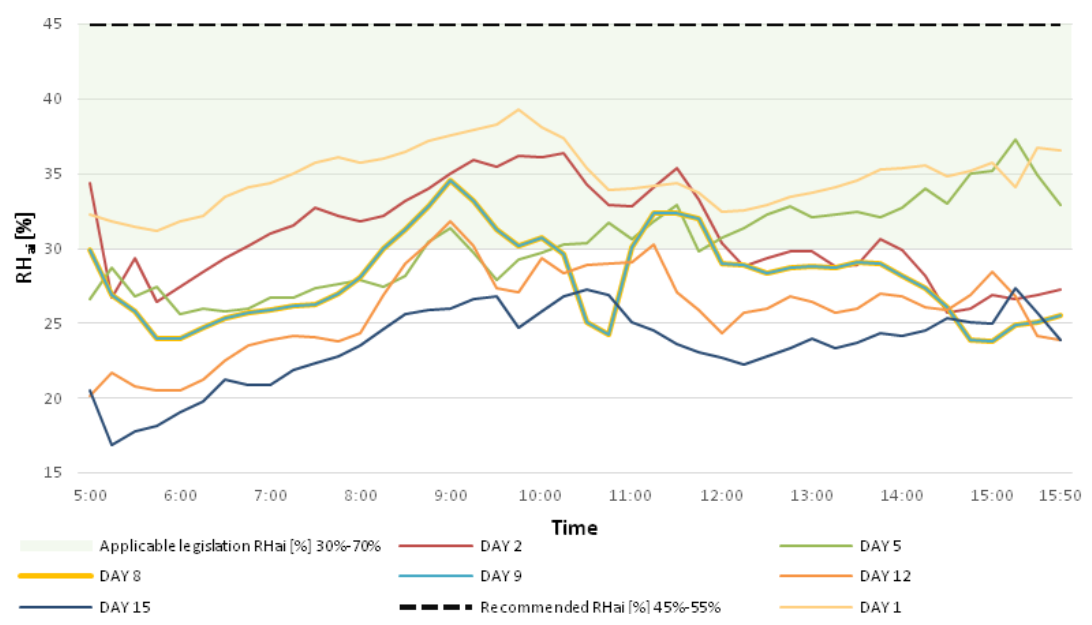

_. Figure 2: Chart, relative air humidity

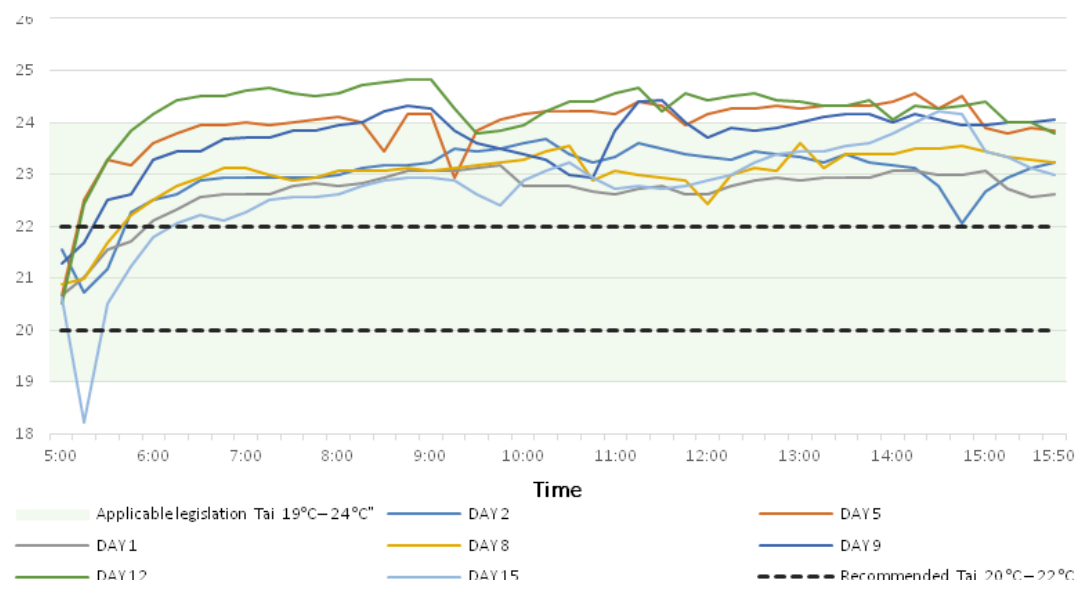

_. Figure 3: Chart, air temperature

The average concentration of carbon dioxide $\mathrm{CO} 2$ [ppm] exceeds recommended value of maximum $1000 \mathrm{ppm}$ every day. Maximal measured values were over $2000 \mathrm{ppm}$. On average, the children are exposed to the carbon dioxide concentration over 1000ppm (Figure 4) more than half a time spent in the kindergarten. Even though this concentration is in line with Slovene legislation, it exceeds recommendations of health organizations, previous studies, etc. This analysis takes into consider- 
ation the time of the actual presence of children in the playroom. The days when the playroom was occupied 50 to $70 \%$ ( 7 and 10 toddlers), the children were exposed to the $\mathrm{CO} 2$ concentration over 1000 ppm more than $1 / 3$ of the time spent in kindergarten. Moreover, the children spent almost $2 / 3$ of their time in kindergarten exposed to the carbon dioxide concentration over $2000 \mathrm{ppm}$ during the days when the playroom was occupied 100 to $110 \%$ ( 14 and 15 toddlers).

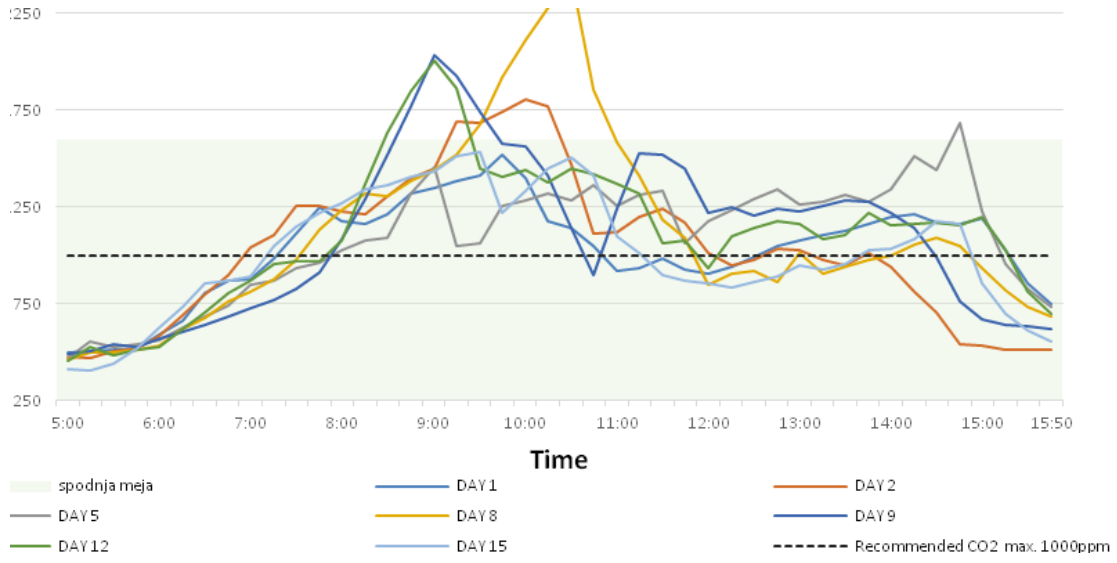

_ Figure 4: Chart, carbon dioxide concentration in the air

The kept record of activities in the group show that the playroom is ventilated three times a day, according to the activities in the kindergarten: before the children entered the playroom (at about 5:00 am), during the time when the children have outdoor activities and the playroom is empty (between 10:00 and 11:00 am) and after the lunch. The measurements show that natural ventilation in the playroom reduce the $\mathrm{CO} 2$ concentration for short time, but it does not achieve the desired level of $\mathrm{CO} 2$. The analysis of the measured parameters proves that the $\mathrm{CO} 2$ concentration in the air decreases rapidly even with the lower number of the occupants in the playroom. The interaction between different parameters of indoor comfort is hard to define, however, it can be concluded that the $\mathrm{CO} 2$ concentration in the air depends on the number of users and it is dramatically increased with the higher number of children. Additionally, this study measures floor surface temperature Tsurf $\left[{ }^{\circ} \mathrm{C}\right]$. The average measured value of the floor temperature is $24.1 \mathrm{C}^{\circ}$ which corresponds the provisions of the Rules on ventilation and air conditioning of buildings which define the floor temperature between $17^{\circ} \mathrm{C}$ and $26^{\circ} \mathrm{C}$.

\section{CONCLUSIONS}

This study analysed elements of IEQ in the chosen kindergarten. Particularly the research deals with indoor air quality and thermal comfort parameters in the kindergarten, which in terms of quality of the indoor living comfort fall into a rather unexplored area. Although studies include analysis of the indoor comfort in kindergartens, they mostly discuss the temperature and the quality of the indoor air in general, whereas continuous measurement for a longer period of time, such as those in this research, can hardly be found.

The parameters of indoor air quality and thermal comfort in the chosen playroom of the kindergarten in Maribor is evaluated according to the legislation and recommendations. The comparison of the measured parameters with the demanded values of the Slovene legislation shows that the indoor air temperature meets prescribed values, while the carbon dioxide concentration in periods during the day exceeds prescribed value and relative air humidity mostly does not achieve the prescribed range value. Moreover, the comparison of the measured parameters with recommendations of health or- 
ganisations, previous studies and international standards leads to the conclusion that the majority of measured values do not meet the recommended values and the indoor environmental quality can be evaluated as poor according to the measured parameters. It can be concluded that the legislation of the Republic of Slovenia is quite insufficient in terms of thermal comfort and indoor air quality in educational, nursery and preschool education. The parameters in the current legislations are determined by general provisions which often do not consider problems of the rooms occupied by children and are less strict than numerous international recommendations.

The results clearly indicate periods of high air temperature, dry air and high level of $\mathrm{CO}$. According to the analyses in this case study, the biggest problem is dry air and increased $\mathrm{CO} 2$ concentration for longer periods of time in the heating season. Based on measurements from this research, the natural ventilation of the room is not sufficient to assure quality of the indoor environmental comfort and should be improved. Improvement should be provided by intensive natural ventilation or with providing additional mechanical systems for ventilation. However, natural room ventilation in winter is aimed only for assuring fresh air, and it is not the way to increase the air humidity. The intensive heating of the playroom results in dry air and overheated playroom, therefore also better control over heating system is recommended.

\section{ACKNOWLEDGMENT}

The presented work was prepared in the frame of the research project "VRTEC + development of the models for renovation of preschool education buildings in Slovenia" which is carried out in the frame of Operational Programme for the Implementation of the EU Cohesion Policy 2014 - 2020. The co-financing of the project was approved in the frame of the open call of the Ministry of Education, Science and Sport of the Republic of Slovenia.

\section{REFERENCES}

- American Society of Heating, Refrigerating and Air Conditioning Engineers (ASHRAE). "INDOOR ENVIRONMENTAL QUALITY IN SCHOOLS AND ACADEMIC PERFORMANCE OF STUDENTS: STUDIES FROM 2004 TO PRESENT. " Accessed December 7, 2019. https://www.ashrae.org

- EPA. 2003. Indoor air quality \& student performance, Indoor Environment Division Office of Radiation And Indoor Air. United States Environmental Protection Agency. Accessed December 10, 2019. https://nepis.epa.gov/Exe/ZyNET.exe/100045VK.TXT?ZyActionD=ZyDocument\&Client=EPA\&Index$=2000+$ Thru $+2005 \&$ Docs $=\&$ Query $=\&$ Time $=\&$ EndTime $=\&$ SearchMethod $=1 \&$ TocRestrict $=$ n $\&$ Toc $=\&$ To cEntry $=\& Q$ Field $=\& Q$ Field Year $=\& Q$ FieldMonth $=\& Q$ FieldDay $=\&$ IntQFieldOp $=0 \&$ ExtQFieldOp $=0 \& X m-$ IQuery $=\&$ File $=\mathrm{D} \% 3 \mathrm{~A} \% 5 \mathrm{Czy}$ files\%5CIndex\%20Data\%5C00thru05\%5CTxt\%5C00000006\%5C100045VK. txt\&User=ANONYMOUS\&Password=anonymous\&SortMethod $=\mathrm{h} \% 7 \mathrm{C} \&$ MaximumDocuments $=1 \&$ FuzzyDegree $=0 \&$ ImageQuality $=\mathrm{r} 75 \mathrm{~g} 8 / \mathrm{r} 75 \mathrm{~g} 8 / \mathrm{x} 150 \mathrm{y} 150 \mathrm{~g} 16 / \mathrm{i} 425 \&$ Display $=\mathrm{hpfr} \&$ DefSeek Page $=x \&$ SearchBack $=Z y$ ActionL\&Back $=Z y$ ActionS\&BackDesc $=$ Results $\% 20$ page \&MaximumPag es $=1 \&$ ZyEntry=1\&SeekPage $=x \& Z y P U R L$

- Fabbri, Kristian. 2013. Thermal comfort evaluation in kindergarten: PMV and PPD measurement through datalogger and questionnaire. Building and Environment, no. 68: 202-214.

- Hagerhed-Engman, Linda, et al. 2006. "Day-care attendance and increased risk for respiratory and allergic symptoms in pre-school age." Allergy 61, no. 4: 447-453.

- Heschong Mahone Group. 1999. "Daylighting in Schools. An investigation into the relationship between daylighting and human performance." Pacific Gas and Electric Company, pp. 29. Accessed November 21, 2019. http://h-m-g.com/downloads/Daylighting/schoolc.pdf

_ Kacjan Žgajnar, Katja, et al. 2013. "Analysis of sanitary-technical and hygienic conditions of Slovenian kindergartens and proposed measures." International Journal of Sanitary Engineering Research 7, no.1: 
4-20.

_ Missia, Daffni A., et al. 2010. "Indoor exposure from building materials: A field study." Atmospheric Environment, no.35: 4388-4395.

_ Municipality of Ljubljana. 2013. "Noise in kindergarten - raising the awareness of children, teachers and parents. The project to preserve and promote the health of children, adolescents and young people" Ljubljana, University of Ljubljana, Faculty of Medicine.

_ Pardee, Mav. 2011. "Building an Infrastructure for Quality: An Inventory of Early Childhood Education and Out-of-School Time Facilities in Massachusetts." Boston, Children's Investment Fund, pp. 43. Accessed November 28, 2019. https://cedac.org/Uploads/Files/CIFBldgInfrastructureReport.pdf

_ Pulmonary and Allergic Patients Association of Slovenia. Accessed December 1, 2019. http://www. dpbs.si/

- Regulation of standards and minimal technical conditions for kindergarten premises and equipment, 1996, Official Gazette of the republic of Slovenia, No. 12/96 and 44/00.

_ Regulations about ventilation and air conditioning in building, 2002, Uradni list RS, št. 42/02 in 105/02.

_ Salvi, S. 2007. "Health effects of ambient air pollution in children." Paediatric Respiratory Reviews, no.8: $275-280$.

- Statistical Office of the Republic of Slovenia SURS. (2019). Preschool education / Actual data. Accessed December 3, 2020. https://www.stat.si/StatWeb/Field/Index/9/83

_ St-Jean, Matthieu, et al. 2012. "Indoor air quality in Montréal area day-care centres, Canada." Environmental Research, no. 118: 1-7.

_ Teli, Despoina, et al. 2012. "Naturally ventilated classrooms: an assessment of existing comfort models for predicting the thermal sensation and preference of primary school children." Energy and Buildings, no. 53: 166-82.

_ WHO Regional Office for Europe. 2007. Development of WHO guidelines for indoor air quality: report on a working group meeting, Bonn, Germany, 17-18, October 2007.

_ Wisconsin department of health services. Accessed November 26, 2019.

_ https://www.dhs.wisconsin.gov/chemical/carbondioxide.htm 